\title{
Mathematical Modeling of a Cs(I) - Sr(II) - Bentonite - Magnetite Sorption System, Simulating the Processes Taking Place in a Deep Geological Repository
}

H. Filipská, K. Štamberg

\begin{abstract}
The derivation of mathematical models of systems consisting of $C s(I)$ or $\operatorname{Sr}(I I)$ and of bentonite $(B)$, magnetite $(M)$ or their mixtures $(B+M)$ are described. The paper deals especially with modeling of the protonation and sorption processes occurring on the functional groups of the solid phase, namely on so called edge sites and layer sites. The two types of sites have different properties and, as a result, three types of Surface Complexation Models (SCM) are used for edge sites, viz. two electrostatic SCMs: the Constant Capacitance Model (CCM) and the Diffusion Double Layer Model (DLM), and one without electrostatic correction: the Chemical Model (CEM). The processes taking place on the layer sites are described by means of the Ion Exchange Model (IExM). In the course of modeling, the speciation of the given metal in the liquid (aqueous) phase has to be taken into account. In principle, the model of protonation or sorption processes is based on the reactions occurring in the aqueous phase and on the surface of the solid phase, and comprises not only the equations of the equilibrium constants of the individual reactions, but also the mass and charge balance equations. The algorithm of the numerical solution is compatible with FAMULUS 3.5 (a Czech software product quite extensively used at Czech universities in the last decade, the bookcase codes of which are utilized).
\end{abstract}

Keywords: cesium, strontium, bentonite, magnetite, surface sorption, ion exchange, protonation, titration, mathematical modeling.

\section{Introduction}

In our deep geological repository, we plan to use canisters made of stainless and carbon steel, with a compacted bentonite barrier. The use of bentonite as a backfill barrier in repositories for nuclear waste is based mainly on its low permeability, swelling properties and capability to significantly retard the migration of most radionuclides $(\mathrm{RN})[1,2,3]$. As a result of corrosion processes, the main corrosion product of steel canisters - magnetite - will also form an important part of the barrier. To be able to predict the fate of $\mathrm{RN}$ in repositories, the retardation processes, i.e. mainly the sorption processes, have to be studied, and mathematical sorption models of the ' $\mathrm{RN}$ bentonite - magnetite' system have to be developed.

The bentonite (clay) surface contains at least two types of surface groups. The first type are permanently charged functional groups created by ionic substitution within the crystal structure. Isomorphic substitution of, e.g. $\mathrm{Al}^{3+}$ for $\mathrm{Si}^{4+}$ within the tetrahedral layer creates a permanent negative charge on the mineral surface, which is compensated externally by cations. These inter-structural-charge surface sites are denoted as layer sites. On the edges of the surface structure, there are $(\equiv \mathrm{SOH})$ sites with a $\mathrm{pH}$-dependent charge. This is due to the "adsorption" of $\mathrm{H}^{+}$ions (then so called protonation proceeds: $\equiv \mathrm{SOH} \rightarrow \equiv \mathrm{SOH}_{2}^{+}$) or "desorption" of $\mathrm{H}^{+}$ions (then deprotonation proceeds: $\equiv \mathrm{SOH} \rightarrow \equiv \mathrm{SO}^{-}$) depending on the $\mathrm{pH}$ of the solution. These variable-charge surface sites are designated as edge sites. These two surface site types are responsible for two uptake processes. The first, on layer sites, tends to be dominant at low $\mathrm{pH}$ and/or high sorbate concentrations. The mechanism of this process is cation exchange.
The second process occurs on edge sites, depending on $\mathrm{pH}$, the mechanism of which is surface complexation. As for magnetite, both types of surface sites were also found [4].

The aim of this work was to derive the mathematical models of the protonation and sorption processes occurring in the 'RN - bentonite - magnetite' system using the FAMULUS software product, including the Newton-Raphson nonlinear regression method [5], and to prepare codes for evaluating the experimental data.

\section{Derivation of models of protonation and sorption processes}

\subsection{Types of models and basic modeling approaches}

In principle, four types of sorption models can be used. The simplest is the $K_{D}$ - model characterizing the linear equilibrium isotherm. The second, e.g. the Langmuir equation, describes the non-linear sorption isotherm. The third is based on the application of a classical chemical-equilibrium equation or equations, e.g., the Ion Exchange Model (IExM). The fourth type is represented by Surface Complexation Models (SCMs) [6, 7, 8]. As was mentioned above, IExM and SCMs describe the processes occurring on layer sites and edge sites, respectively, and as a result, they can be designated as the most important models.

At least three types of surface complexation models (SCMs), namely two electrostatic models, the Constant Capacitance Model (CCM) and the Diffuse Double Layer Model (DLM) and one chemical equilibrium, non-electrostatic 
model (CEM), were employed to simulate the amphoteric property of the solid phase types of bentonite, goethite and montmorillonite, and to describe the sorption of different metal ions and their complex compounds from an aqueous solution as a function of $\mathrm{pH}$, ionic strength, solution concentration, etc. Well developed SCMs enable the behaviour of systems, e.g. RN-bentonite-magnetite, to be quantitatively described and the sorption processes to be simulated.

SCMs and IExMs are based on the following suppositions:

- No mutual interactions exist between particles adsorbed on the surface of the solid phase.

- The protonation and deprotonation processes depend on $\mathrm{pH}$.

- On the surface of the solid phase (e.g. bentonite), as was mentioned above, there are two types of functional groups, i.e. so called edge sites and layer sites.

- The functionality of adsorption sites, i.e. edge sites or layer sites, is identical.

- The concentration of the $i$ th-component in the aqueous phase near the surface (in the aqueous layer adhering to the surface) is given by the Boltzman equation (1):

$$
\left(C_{i}\right)_{S}=C_{i} \cdot \exp \left(-\frac{z \cdot \psi \cdot F}{R \cdot T}\right)
$$

where $\left(C_{i}\right)_{S}$ is the concentration near the surface, $C_{i}$ is the so-called bulk concentration of the $i$ th-component, $z$ is the charge of the $i$ th-component, $\psi$ is the electrostatic potential, $F$ is the Faraday constant, $R$ is the gas constant and $T$ is the absolute temperature.

- Between the surface charge, $\sigma$, and the electrostatic potential, $\psi$, the following dependencies hold $(2,3,4)$ :

$$
\begin{array}{ll}
\sigma=G \cdot \psi & \text { (in the case of CCM) } \\
\sigma=0.1174 \cdot I^{1 / 2} \cdot \sinh \left(\frac{z_{i} \cdot \psi \cdot F}{2 R \cdot T}\right) & \text { (in the case of DLM) } \\
\psi=0 & \text { (in the case of CEM) }
\end{array}
$$

where $G$ is the so-called Helmholtz capacitance.

In order to apply SCMs for describing the sorption processes occurring in the system type of e.g. RN-bentonite-magnetite, we need the surface area of each solid phase component, the total surface site concentrations (edge and layer sites) and the protonation constant (for edge sites) and ion exchange constant (for layer sites). These can be obtained by evaluating the acid-base titration data (in our case of bentonite and magnetite and their mixtures) and by measuring the surface area. In the course of evaluating the of sorption experimental data, specifically the sorption dependencies on $\mathrm{pH}$, the values of the equilibrium constants of the surface complexation reactions are found.

As for the modeling approaches used in the case of RN-bentonite-magnetite type system, two different procedures can be tested:

- The Generalized Composite Approach (GC), where the given mixture of solid phase components, e.g. bentonite + magnetite, is considered as a compact sorbent characterized by a single set of titration and sorption parameters, which are sought by direct fitting of the experimental data.

- The Component Additivity Approach (CA), composed of a weighted combination of models describing the protona- tion + ion exchange (on layer sites) and the sorption on individual solid phase components, e.g. on bentonite and magnetite. The individual parameters have to be obtained by fitting the appropriate experimental data that are valid for the solid component.

It is evident that the GC Approach demands less experimental time than the CA Approach because we need only one titration curve and one sorption pH-dependency for the given mixture of solid components. On the other hand, if the protonation + ion exchange and sorption quantities characterizing the individual solid phase (mineralogical) components are determined, the CA Approach enables the sorption behaviour of selected component mixtures to be simulated. It is also evident that the codes corresponding to both the GC and the CA approaches are in principle different: whereas the GC Approach code has to be based on a non-linear regression procedure, the CA Approach code is relatively simple, even if internal iterative loops also have to be used.

\subsection{Modeling of titration curves}

Description of the system

$$
\begin{aligned}
& \mathrm{SO}^{-}+\mathrm{H}^{+} \leftrightarrow \mathrm{SOH}^{0} \\
& \mathrm{SOH}^{0}+\mathrm{H}^{+} \leftrightarrow \mathrm{SOH}_{2}^{+} \\
& X \mathrm{Na}+\mathrm{H}^{+} \leftrightarrow X \mathrm{H}+\mathrm{Na}^{+}
\end{aligned}
$$

where $\mathrm{SO}^{-}, \mathrm{SOH}$ and $\mathrm{SOH}_{2}^{+}$are symbols for edge sites, and $X^{-}$is the symbol for layer sites.

In the course of titration, protonation reactions (5) and (6) on the edge sites, and the ion exchange reaction (7) on the layer sites are under way in the system. Titration occurs under an inert atmosphere (e.g. $\mathrm{N}_{2}$ ), and as a result, the presence of atmospheric $\mathrm{CO}_{2}$ need not be taken into account. The determination of the titration curve starts at approx. $\mathrm{pH} 7$, namely the titration of an aqueous suspension of the solid phase, having a given ionic strength, with both $\mathrm{HCl}$ and $\mathrm{NaOH}$ solutions such that the total titration curve consists of two parts - two sets of experimental points obtained with both $\mathrm{HCl}$ and $\mathrm{NaOH}$.

\section{Derivation of CEM, CCM and DLM titration models}

It is supposed that the electroneutrality represented by Eq. (8) exists between positive and negative charged surface groups and negative and positive charged species in solution in the course of titration.

$$
\begin{aligned}
& m \cdot\left[\mathrm{SOH}_{2}^{+}\right]+V_{\Sigma} \cdot\left(\left[\mathrm{H}^{+}\right]+\left[C_{b}\right]\right) \\
& =m \cdot\left(\left[\mathrm{SO}^{-}\right]+\left[X^{-}\right]\right)+V_{\Sigma} \cdot\left(\left[\mathrm{OH}^{-}\right]+\left[C_{a}\right]\right)
\end{aligned}
$$

By rearrangement of Eq. (8) we can obtain Eq. (9). It describes the course of titration relating the surface charge, $Q$ $[\mathrm{mol} / \mathrm{kg}]$, and the experimentally measurable parameters:

$$
\begin{aligned}
& Q \equiv\left[\mathrm{SOH}_{2}^{+}\right]-\left[\mathrm{SO}^{-}\right]-\left[X^{-}\right] \\
& =\frac{V_{\Sigma}}{m}\left(\left[C_{a}\right]-\left[C_{b}\right]+\left[\mathrm{OH}^{-}\right]-\left[\mathrm{H}^{+}\right]\right) \\
& {\left[C_{a}\right]=\frac{v_{\mathrm{H}} \cdot c_{\mathrm{H}}}{V_{\Sigma}}}
\end{aligned}
$$


$\left[C_{b}\right]=\frac{v_{\mathrm{OH}} \cdot c_{\mathrm{OH}}}{V_{\Sigma}}$,

where $V_{\Sigma}\left(=V_{0}+v_{\mathrm{H}}+v_{\mathrm{OH}}\right)$ is the total volume and $V_{0}$ is the starting volume of the aqueous phase $\left[\mathrm{dm}^{3}\right] ; m$ is the mass of the solid phase $[\mathrm{kg}] ;\left[C_{a}\right]$ and $\left[C_{b}\right]$ are the bulk concentrations of acid (i.e. of $\left[\mathrm{Cl}^{-}\right]$) and caustic soda (i.e. of $\left[\mathrm{Na}^{+}\right]$), respectively, in solution $\left[\mathrm{mol} \cdot \mathrm{dm}^{-3}\right] ; c_{\mathrm{H}}$ and $c_{\mathrm{OH}}$ are the concentrations, $\left[\mathrm{mol} \cdot \mathrm{dm}^{-3}\right]$, of hydrochloric acid, $\mathrm{HCl}$, and caustic soda, $\mathrm{NaOH}$, respectively, used in titration; $v_{\mathrm{H}}$ and $v_{\mathrm{OH}}$ are the consumptions, $\left[\mathrm{dm}^{3}\right]$, of acid and caustic soda, respectively, in the course of titration.

Eq. (9) consists of two parts: the right-hand side can be designated as the experimentally determined values of the surface charge, $Q_{\text {exp }}$, and the left-hand side expresses the sum of the two values of the surface charges, $Q_{\mathrm{cal}}\left(=Q_{\mathrm{ES}}+Q_{\mathrm{LS}}\right)$, namely the charge of the edge sites, $Q_{\mathrm{ES}}\left(=\left[\mathrm{SOH}_{2}^{+}\right]-\left[\mathrm{SO}^{-}\right]\right)$ and the charge of the layer sites, $Q_{\mathrm{LS}}\left(=-\left[\mathrm{X}^{-}\right]\right)$. The function $\left(Q_{\text {exp }}\right)_{i}=\mathrm{f}\left(p \mathrm{H}_{i}\right)$ or $\left(Q_{\exp }\right)_{i}=\mathrm{f}\left(\left[\mathrm{H}^{+}\right]_{i}\right), i=1,2, \ldots, n p$, describes the experimental titration curve, consisting of $n p$ experimental points. The goal of modeling the titration curve is to construct the function $Q_{\mathrm{cal}}=\mathrm{f}\left(\left[\mathrm{H}^{+}\right]\right)$applicable for fitting of experimental data and for determining of the values of the protonation and ion exchange constants, and the total concentrations of the edge sites and layer sites in the given solid phase. As for the numerical method, the acid-base titration data are fitted by the Newton-Raphson multidimensional non-linear regression method and the quantity WSOS/DF (see Eqs. (83) and (84)) is used as the criterion for the goodness-of-fit.

\section{Derivation of $Q_{\text {cal }}=f\left(\left[\mathrm{H}^{+}\right]\right)$using CEM (Chemical Equilibrium Model)}

As was mentioned above, it is assumed that in the case of CEM $\psi=0$ and as a result, the concentrations of the $i$ th-components existing near the surface, $\left(C_{i}\right)_{S}$, equals the bulk concentrations, $C_{i}$ (see Eq. (1)).

The protonation constants of the edge sites, $K S 1$ and $K S 2$, are given by Eqs. (12) and (13), respectively. Now, using the balance equation (14) for the total concentration of the edge sites, $\Sigma \mathrm{SOH}$, together with Eqs. (12) and (13), we derive Eq. (15) corresponding to the function $Q_{\mathrm{ES}}=\mathrm{f}\left(\left[\mathrm{H}^{+}\right]\right)$:

$\mathrm{SO}^{-}+\mathrm{H}^{+} \leftrightarrow \mathrm{SOH}^{0}, K S 1=\frac{\left[\mathrm{SOH}^{0}\right]}{\left[\mathrm{SO}^{-}\right] \cdot\left[\mathrm{H}^{+}\right]}$,

$\mathrm{SOH}^{0}+\mathrm{H}^{+} \leftrightarrow \mathrm{SOH}_{2}^{+}, K S 2=\frac{\left[\mathrm{SOH}_{2}^{+}\right]}{\left[\mathrm{SOH}^{0}\right] \cdot\left[\mathrm{H}^{+}\right]}$,

$\Sigma \mathrm{SOH}=\left[\mathrm{SOH}_{2}^{+}\right]+\left[\mathrm{SOH}^{0}\right]+\left[\mathrm{SO}^{-}\right]$,

$Q_{\mathrm{ES}}=\frac{\Sigma \mathrm{SOH}\left(K S 1 \cdot K S 2 \cdot\left[\mathrm{H}^{+}\right]^{2}-1\right)}{\left(1+K S 1 \cdot\left[\mathrm{H}^{+}\right]+K S 1 \cdot K S 2 \cdot\left[\mathrm{H}^{+}\right]^{2}\right)}\left[\mathrm{mol} \cdot \mathrm{kg}^{-1}\right]$.

The surface charge can also be expressed in coulomb per $\mathrm{m}^{2}, \sigma_{\mathrm{ES}}\left[\mathrm{C} \cdot \mathrm{m}^{-2}\right]$ :

$$
\sigma_{\mathrm{ES}}=Q_{\mathrm{ES}} \frac{F}{S P}\left[\mathrm{C} \cdot \mathrm{m}^{-2}\right] .
$$

As regards layer sites, the ion exchange reaction takes place on these sites, and the equilibrium constant, KS5, is given by Eq. (17). Furthermore, the dissociation of $X \mathrm{H}$ and $X \mathrm{Na}$ according to equations (18) and (19), respectively, needs to be taken into consideration. On the basis of the literature data, it is supposed that for the corresponding values of the dissociation constants, it holds: $K S 5 b \gg K S 5 a$ and $K S 5 a \leq 10^{-2}$. It follows from this that the dissociation of $X \mathrm{H}$ can be neglected and that the concentration of $X \mathrm{Na}$ is very low and therefore $X \mathrm{Na}$ is practically dissociated.

$$
\begin{array}{ll}
X \mathrm{Na}+\mathrm{H}^{+} \leftrightarrow X \mathrm{H}+\mathrm{Na}^{+}, & K S 5=\frac{[X \mathrm{H}] \cdot\left[\mathrm{Na}^{+}\right]}{[X \mathrm{Na}] \cdot\left[\mathrm{H}^{+}\right]}, \\
X \mathrm{H} \leftrightarrow X^{-}+\mathrm{H}^{+}, & K S 5 b=\frac{\left[X^{-}\right] \cdot\left[\mathrm{H}^{+}\right]}{[X \mathrm{H}]}, \\
X \mathrm{Na} \leftrightarrow X^{-}+\mathrm{Na}^{+}, & K S 5 b=\frac{\left[X^{-}\right] \cdot\left[\mathrm{Na}^{+}\right]}{[X \mathrm{Na}]} .
\end{array}
$$

If the function $Q_{\mathrm{LS}}=\mathrm{f}\left(\left[\mathrm{H}^{+}\right]\right)$is to be derived, two balance equations are needed, viz., the first balances the layer sites, cf. Eq. (20) for total concentration of layer sites $\Sigma \mathrm{X}$, and the second balances the sodium ions, cf. Eq. (21) from which Eq. (22) can be obtained.

$$
\begin{aligned}
& \begin{aligned}
\Sigma X= & {[X \mathrm{Na}]+[X \mathrm{H}] \cong\left[X^{-}\right]+[X \mathrm{H}], } \\
\Sigma \mathrm{Na} & \equiv m \cdot\left[X \mathrm{Na}_{0}\right]+V_{0}\left[\mathrm{Na}_{0}\right]+v_{\mathrm{OH}} \cdot c_{\mathrm{OH}} \\
& =m \cdot[X \mathrm{Na}]+V_{\Sigma}\left[\mathrm{Na}^{+}\right],
\end{aligned} \\
& {\left[\mathrm{Na}^{+}\right]=\frac{V_{0}\left[\mathrm{Na}_{0}\right]+v_{\mathrm{OH}} \cdot c_{\mathrm{OH}}-m\left([X \mathrm{Na}]-\left[X \mathrm{Na}_{0}\right]\right)}{V_{\Sigma}} .}
\end{aligned}
$$

In our case, the starting concentration $\left[\mathrm{Na}_{0}\right]$ equals the starting value of the ionic strength achieved by adding $\mathrm{NaNO}_{3}$, or $\mathrm{NaClO}_{4}$ and as for $\left[X \mathrm{Na}_{0}\right]$, if the starting $\mathrm{pH}$ of titration is approx. 7 , it is assumed to be approximately equal to the value of $\Sigma X$ (cf. Eq. (20)).

$Q_{\mathrm{LS}}=\left[X^{-}\right] \cong[X \mathrm{Na}]=\frac{\Sigma X\left[\mathrm{Na}^{+}\right]}{\left[\mathrm{Na}^{+}\right]+K S 3 \cdot\left[\mathrm{H}^{+}\right]}\left[\mathrm{mol} \cdot \mathrm{kg}^{-1}\right]$

Also in this case, the surface charge can be expressed in Coulomb per $\mathrm{m}^{2}, \sigma_{\mathrm{LS}}$ :

$\sigma_{\mathrm{LS}}=Q_{\mathrm{LS}} \cdot \frac{F}{S P}\left[\mathrm{C} \cdot \mathrm{m}^{-2}\right]$.

It is evident that the function $Q_{\mathrm{LS}}=\mathrm{f}\left(\left[\mathrm{H}^{+}\right]\right)$is given by the combination of Eqs. (23) and (22).

Altogether, the CEM function of the titration curve, namely $Q_{\mathrm{cal}}=Q_{\mathrm{ES}}+Q_{\mathrm{LS}}=\mathrm{f}\left(\left[\mathrm{H}^{+}\right]\right)$, which can be used for evaluating the experimental data, consists of equations (15), (22) and (23). Formally, the total surface charge in Coulomb per $\mathrm{m}^{2}$, $\sigma_{\Sigma}$, can be given by Eq. (25):

$\sigma_{\mathrm{cal}}=Q_{\mathrm{cal}} \cdot \frac{F}{S P}\left[\mathrm{C} \cdot \mathrm{m}^{2}\right]$.

\section{Derivation of $Q_{\text {cal }}=f\left(\left[\mathrm{H}^{+}\right]\right)$using $C C M$ (Constant Capacitance Model)}

In principle, the construction of this model function is congruent with the construction of the CEM model. However, the value of electrostatic potential $\psi$ does not equal zero and 
the Boltzman equation, Eq. (1), has to be used for calculating the component concentrations existing near the surface, $\left(C_{i}\right)_{\mathrm{S}}$. These are then inserted into the model equations (15), (22) and (23) instead of the bulk concentrations.

First, quantity $\psi$ must be calculated, namely by means of equations (2) and (25). After the rearrangement procedure, equation (26) is obtained, for the solution of which a suitable interpolation method has to be used.

$$
\begin{aligned}
& \frac{Q_{\mathrm{cal}} \cdot F}{S P}-\psi \cdot G=0 \\
& Q_{\mathrm{cal}}=\frac{\Sigma \mathrm{SOH}\left(K S 1 \cdot K S 2 \cdot\left[\mathrm{H}_{\mathrm{S}}^{+}\right]^{2}-1\right)}{\left(1+K S 1 \cdot\left[\mathrm{H}_{\mathrm{S}}^{+}\right]+K S 1 \cdot K S 2 \cdot\left[\mathrm{H}_{\mathrm{S}}^{+}\right]^{2}\right)} \\
& \quad-\frac{\Sigma X \cdot\left[\mathrm{Na}_{\mathrm{S}}^{+}\right]}{K S 3 \cdot\left[\mathrm{H}_{\mathrm{S}}^{+}\right]+\left[\mathrm{Na}_{\mathrm{S}}^{+}\right]}\left[\mathrm{mol} \cdot \mathrm{kg}^{-1}\right], \\
& {\left[\mathrm{H}_{\mathrm{S}}^{+}\right]=\left[\mathrm{H}^{+}\right] \cdot \exp \left(-\frac{\psi F}{R T}\right)} \\
& {\left[\mathrm{Na}_{\mathrm{S}}^{+}\right]=\left[\mathrm{Na}^{+}\right] \cdot \exp \left(-\frac{\psi F}{R T}\right)}
\end{aligned}
$$

where the symbols with subscript "s" mean the concentrations near the surface.

The proper CCM model function consists of four equations, namely (26), (27), (28a) and (28b). The values of the quantities searched, viz. $K S 1, K S 2, K S 3, \Sigma \mathrm{SOH}, \Sigma X$ and $G$, are determined in the course of simultaneous solution of the above mentioned equations using a non-linear regression procedure.

\section{Derivation of $Q_{c a l}=f\left(\left[H^{+}\right]\right)$using DLM (Diffuse Layer Model)}

Similar to CCM, quantity $\psi$ must first be calculated using Eqs. (3) and (25) rearranged into the form of Eq. (29):

$\frac{Q_{\mathrm{cal}} \cdot F}{S P}-\left[0.1174 \sqrt{I} \cdot \sinh \left(\frac{\psi F}{2 R T}\right)\right]=0$

The proper DLM model function consists of four equations, namely (29), (27), (28a) and (28b), which can subsequently be used for determining $K S 1, K S 2, K S 3, \Sigma \mathrm{SOH}$ and $\Sigma X$ by the procedure described above.

\subsection{Modeling of $p H$ dependences of sorption}

\section{Description of the system}

The derivation of SCMs (CEM, CCM, DLM) for sorption of strontium on bentonite or magnetite will be demonstrated, as an example. The sorption experiments are carried out in a mixed batch reactor under given conditions, i.e., under given values of the starting volume, $V_{0}$, and composition of the aqueous phase (as a starting solution, synthetic granitic water is used) and mass of solid phase, $m$. The value of the given ionic strength, $I$, is adjusted using $\mathrm{NaNO}_{3}$. The reaction time (time of contact of the phases, e.g. approx. 30 days) must be sufficient for equilibrium to be reached. Because the system is open to the atmosphere, the influence of atmospheric partial pressure of $\mathrm{CO}_{2}$ is taken into consideration, especially if $\mathrm{pH}$ is greater than approx. 8.2. In the course of the sorption experi- ment, the influence of $\mathrm{pH}$ is observed, namely in such a way that each experimental point has a given $\mathrm{pH}$, the value of which is adjusted by means of $0.1 \mathrm{M} \mathrm{HCl}$ or $0.1 \mathrm{M} \mathrm{NaOH}$.

The sorption phenomenon is observed to proceed with the formation of a surface complex, or complexes, including ion exchange on the layer sites, as described below, between the surface groups and various species of strontium $\left(\mathrm{Sr}^{2+}\right.$, $\mathrm{SrCO}_{3}^{0}, \mathrm{SrNO}_{3}^{+}$) present in the experimental solution. These species compete with each other to form a surface complex with the solid phase, and the values of the corresponding equilibrium constants quantify this competition. The input data include among others the protonation and ion exchange constants and the total concentrations of the edge and layer sites, or the Helmholtz capacitance, determined in the course of evaluating the titration curve $(K S 1, K S 2, K S 5, \Sigma \mathrm{SOH}, \Sigma X$, or $G)$.

\section{Derivation of CEM, CCM and DLM sorption models}

The experimental sorption data are in the form: $K d_{\text {exp }}=\mathrm{f}\left(p H_{\text {exp }}\right)$ or $\%$ Sorption $_{\text {exp }}=\mathrm{f}\left(p H_{\text {exp }}\right)$, where $K d_{\text {exp }}$ is the distribution coefficient of sorption of $\mathrm{Sr}(\mathrm{II})$ and \% Sorption ${ }_{\text {exp }}$ expresses the sorption of $\mathrm{Sr}(\mathrm{II})$ in percentage units. As a result, the analogous model function, namely $K d_{\text {cal }}=\mathrm{f}(p H)$ or \% Sorption $_{\text {cal }}=\mathrm{f}(p H)$, has to be derived using the following procedure.

\begin{tabular}{|c|c|c|}
\hline Reactions on edge-sites & & \\
\hline $\mathrm{SO}^{-}+\mathrm{H}^{+} \leftrightarrow \mathrm{SOH}^{0}$ & $(K S 1)$ & see Eq. (5 \\
\hline $\mathrm{SOH}^{0}+\mathrm{H}^{+} \leftrightarrow \mathrm{SOH}_{2}^{+}$ & $(K S 2)$ & see Eq. $(6$ \\
\hline $\mathrm{SOH}_{2}^{+}+\mathrm{CO}_{3}^{2-} \leftrightarrow \mathrm{SOH}_{2} \mathrm{CO}_{3}^{-}$ & $(K S 3)$ & \\
\hline $\mathrm{SOH}_{2}^{+}+\mathrm{HCO}_{3}^{-} \leftrightarrow \mathrm{SOH}_{2} \mathrm{HCO}_{3}^{0}$ & $(K S 4)$ & \\
\hline $\mathrm{SO}^{-}+\mathrm{Sr}^{2+} \leftrightarrow \mathrm{SOSr}^{+}$ & $(K S r 1)$ & \\
\hline $2 \mathrm{SO}^{-}+\mathrm{Sr}^{2+} \leftrightarrow(\mathrm{SO})_{2} \mathrm{Sr}^{0}$ & $(K S r 2)$ & \\
\hline $\mathrm{SO}^{-}+\mathrm{SrNO}_{3}^{+} \leftrightarrow \mathrm{SOSrNO}_{3}^{0}$ & $(K S r 3)$ & \\
\hline $\mathrm{SO}^{-}+\mathrm{SrCO}_{3}^{0} \leftrightarrow \mathrm{SOSrCO}_{3}^{-}$ & $(\mathrm{KSr} 4)$ & \\
\hline
\end{tabular}

Firstly, let the reactions occurring on the solid phase (e.g. bentonite) and in the aqueous solution be formulated (the symbols for the corresponding equilibrium constants are given in parenthesis):

$\underline{\text { Reactions on layer-sites }}$

$X \mathrm{H}+\mathrm{Na}^{+} \leftrightarrow X \mathrm{Na}+\mathrm{H}^{+}$

(KS5) see Eq. (7)

$2 \mathrm{XH}+\mathrm{Sr}^{2+} \leftrightarrow X_{2} \mathrm{Sr}+2 \mathrm{H}^{+}$

$(\operatorname{KSr} 5)$

$X \mathrm{H}+\mathrm{SrNO}_{3}^{+} \leftrightarrow X_{\mathrm{SrNO}_{3}}+\mathrm{H}^{+}$

$(\operatorname{KSr} 6)$

$\underline{\text { Reactions in an aqueous solution }}$

$\mathrm{Sr}^{2+}+\mathrm{CO}_{3}^{2-} \leftrightarrow \mathrm{SrCO}_{3}^{0}$

$\mathrm{Sr}^{2+}+\mathrm{NO}_{3}^{-} \leftrightarrow \mathrm{SrNO}_{3}^{+}$

$\mathrm{Sr}^{2+}+\mathrm{SO}_{4}^{2-} \leftrightarrow \mathrm{SrSO}_{4}^{0}$

$\mathrm{Sr}^{2+}+\mathrm{CO}_{3}^{2-} \leftrightarrow \mathrm{SrCO}_{3}$. solid

$\mathrm{H}^{+}+\mathrm{CO}_{3}^{2-} \leftrightarrow \mathrm{HCO}_{3}^{-}$

$2 \mathrm{H}^{+}+\mathrm{CO}_{3}^{2-} \leftrightarrow \mathrm{H}_{2} \mathrm{CO}_{3}$

$2 \mathrm{H}^{+}+\mathrm{CO}_{3}^{2-} \leftrightarrow \mathrm{CO}_{2}\left(+\mathrm{H}_{2} \mathrm{O}\right)$ 
$\mathrm{H}_{2} \mathrm{O} \leftrightarrow \mathrm{H}^{+}+\mathrm{OH}^{-}$

$(K w)$

Secondly, the equilibrium constants of the reactions mentioned above have to be established:

Constants holding for edge-sites (using the Boltzman equa$\underline{\operatorname{tion}(1)):}$

$$
\begin{aligned}
K S 1 & =\frac{\left[\mathrm{SOH}^{0}\right]}{\left[\mathrm{SO}^{-}\right] \cdot\left[\mathrm{H}_{\mathrm{S}}^{+}\right]} \\
& =\left(\frac{\left[\mathrm{SOH}^{0}\right]}{\left[\mathrm{SO}^{-}\right] \cdot\left[\mathrm{H}^{+}\right]}\right) \cdot \exp \left(\frac{\psi F}{R T}\right)
\end{aligned}
$$$$
K S 2=\left(\frac{\left[\mathrm{SOH}_{2}^{+}\right]}{\left[\mathrm{SOH}^{0}\right] \cdot\left[\mathrm{H}^{+}\right]}\right) \cdot \exp \left(\frac{\psi F}{R T}\right)
$$

$K S 3=\left(\frac{\left[\mathrm{SOH}_{2} \mathrm{CO}_{3}^{-}\right]}{\left[\mathrm{SOH}_{2}^{+}\right] \cdot\left[\mathrm{CO}_{3}^{-}\right]}\right) \cdot \exp \left(-\frac{2 \psi F}{R T}\right)$

$K S 4=\left(\frac{\left[\mathrm{SOH}_{2} \mathrm{HCO}_{3}^{0}\right]}{\left[\mathrm{SOH}_{2}^{+}\right] \cdot\left[\mathrm{HCO}_{3}^{-}\right]}\right) \cdot \exp \left(-\frac{\psi F}{R T}\right)$

$K S r 1=\left(\frac{\left[\mathrm{SOSr}^{+}\right]}{\left[\mathrm{SO}^{-}\right] \cdot\left[\mathrm{Sr}^{2+}\right]}\right) \cdot \exp \left(\frac{2 \psi F}{R T}\right)$

$K S r 2=\left(\frac{\left[\left(\mathrm{SO}_{2}\right)_{2} \mathrm{Sr}^{0}\right]}{\left[\mathrm{SO}^{-}\right]^{2} \cdot\left[\mathrm{Sr}^{2+}\right]}\right) \cdot \exp \left(\frac{2 \psi F}{R T}\right)$

$K S r 3=\left(\frac{\left[\mathrm{SOSrNO}_{3}^{0}\right]}{\left[\mathrm{SO}^{-}\right] \cdot\left[\mathrm{SrNO}_{3}^{+}\right]}\right) \cdot \exp \left(\frac{\psi F}{R T}\right)$

$\operatorname{KSr} 4=\left(\frac{\left[\mathrm{SOSrCO}_{3}^{-}\right]}{\left[\mathrm{SO}^{-}\right] \cdot\left[\mathrm{SrCO}_{3}^{0}\right]}\right)$

Constants holding for layer sites:

$K \operatorname{Sr} 5=\left(\frac{\left[X_{2} \mathrm{Sr}\right] \cdot\left[\mathrm{H}^{+}\right]^{2}}{[\mathrm{XH}]^{2} \cdot\left[\mathrm{Sr}^{2+}\right]}\right)$

$K \operatorname{Kr} 6=\left(\frac{\left[\mathrm{XSrNO}_{3}\right] \cdot\left[\mathrm{H}^{+}\right]}{[\mathrm{XH}]^{2} \cdot\left[\mathrm{SrNO}_{3}^{+}\right]}\right)$

Constants of reactions occurring in an aqueous solution (for $\underline{I=0)}$ :

$K L 1=\left(\frac{\left[\mathrm{SrCO}_{3}^{0}\right]}{\left[\mathrm{Sr}^{2+}\right] \cdot\left[\mathrm{CO}_{3}^{2-}\right]}\right)$

$K L 2=\left(\frac{\left[\mathrm{SrNO}_{3}^{+}\right]}{\left[\mathrm{Sr}^{2+}\right] \cdot\left[\mathrm{NO}_{3}^{-}\right]}\right)$

$K L 3=\left(\frac{\left[\mathrm{SrSO}_{4}^{0}\right]}{\left[\mathrm{Sr}^{2+}\right] \cdot\left[\mathrm{SO}_{4}^{2-}\right]}\right)$
$S R=\left[\mathrm{Sr}^{2+}\right] \cdot\left[\mathrm{CO}_{3}^{2-}\right]$

$K w=\left[\mathrm{H}^{+}\right] \cdot\left[\mathrm{OH}^{-}\right]$

$K 8=\left(\frac{\left[\mathrm{HCO}_{3}^{-}\right]}{\left[\mathrm{H}^{+}\right] \cdot\left[\mathrm{CO}_{3}^{2-}\right]}\right)$

$K 9=\left(\frac{\left[\mathrm{H}_{2} \mathrm{CO}_{3}^{0}\right]}{\left[\mathrm{H}^{+}\right]^{2} \cdot\left[\mathrm{CO}_{3}^{2-}\right]}\right)$

$K p=\frac{p \mathrm{CO}_{2}}{\left[\mathrm{CO}_{3}^{2-}\right] \cdot\left[\mathrm{H}^{+}\right]^{2}}$

Where SR is the solubility product of $\mathrm{SrCO}_{3}$. solid and $p \mathrm{CO}_{2}$ is the partial pressure of $\mathrm{CO}_{2}$ (in our case, it deals with atmospheric partial pressure).

The Davies equation (64) for the $i$-th ionic species and the Hegelson equation (65) for the $i$-th neutral species are used for calculating the activity coefficients by means of which the values of the equilibrium constants are corrected for the given ionic strength, $I$.

$\log f_{i}=-A \cdot z_{i}^{2}\left(\frac{\sqrt{I}}{1+\sqrt{I}}-0.24 I\right)$,

where $A=0.509$ (holds for aqueous solutions and ambient temperature),

$\log f_{i}=b \cdot I \quad($ where $b=0.01-0.10)$.

Thirdly, the balance equations are formulated:

Balance equation of the surface charge, $\sigma$ :

$$
\begin{aligned}
\sigma= & \left(\left[\mathrm{SOH}_{2}^{+}\right]+\left[\mathrm{SOSr}^{+}\right]-\left[\mathrm{SO}^{-}\right]\right. \\
& \left.-\left[\mathrm{SOSrCO}_{3}^{-}\right]-\left[\mathrm{SOH}_{2} \mathrm{CO}_{3}^{-}\right]\right) \cdot \frac{F}{S P} \quad\left[\mathrm{C} \cdot \mathrm{m}^{-2}\right]
\end{aligned}
$$

It is evident that only charged surface species are taken into consideration. As was described above in connection with the derivation of the CCM and DLM models, it is necessary the quantity $\psi$ needs to be determined, namely by solving Eqs. (67) and (68) originating from combination of Eq. (66) with Eq. (3) or (2), respectively. Depending on the type of surface complexation model, the obtained value of $\psi$ is then inserted into Eqs. (46)-(52).

$$
\begin{array}{ll}
\text { DLM: } & \sigma-0.1174 \cdot \sqrt{I} \cdot \sinh \frac{\psi F}{2 R T}=0 \\
\text { CCM: } & \sigma-\psi \cdot G=0 \\
\text { CEM: } & \sigma=0 \text { i.e. } \quad \psi=0
\end{array}
$$

Balance equation of total concentration of the edge sites, $\underline{\mathrm{SOH}}$ :

$$
\begin{aligned}
\Sigma \mathrm{SOH}= & {\left[\mathrm{SOH}_{2}^{+}\right]+[\mathrm{SOH}]+\left[\mathrm{SO}^{-}\right]+\left[\mathrm{SOSr}^{+}\right] } \\
& +2\left[(\mathrm{SO})_{2} \mathrm{Sr}^{0}\right]+\left[\mathrm{SOSrNO}_{3}^{0}\right]+\left[\mathrm{SOSrCO}_{3}^{-}\right] \\
& +\left[\mathrm{SOH}_{2} \mathrm{CO}_{3}^{-}\right]+\left[\mathrm{SOH}_{2} \mathrm{HCO}_{3}^{0}\right] .
\end{aligned}
$$


Balance equation of concentration of $\mathrm{Sr}$ (II) in the aqueous phase, $[\mathrm{Sr}]^{\text {solution: }}$

$[\mathrm{Sr}]^{\text {solution }}=\left[\mathrm{Sr}^{2+}\right]+\left[\mathrm{SrCO}_{3}^{0}\right]+\left[\mathrm{SrNO}_{3}^{+}\right]+\left[\mathrm{SrSO}_{4}^{0}\right]$.

Balance equation of the total concentration of $\mathrm{Sr}(\mathrm{II})$ in the solution, $[\Sigma \mathrm{Sr}]^{\text {solution }}$, including the precipitate:

$$
\begin{aligned}
{[\Sigma \mathrm{Sr}]^{\text {solution }} } & =\left[\mathrm{Sr}^{2+}\right]+\left[\mathrm{SrCO}_{3}^{0}\right]+\left[\mathrm{SrNO}_{3}^{+}\right] \\
& +\left[\mathrm{SrSO}_{4}^{0}\right]+\left[\mathrm{SrCO}_{3} . \text { solid }\right]
\end{aligned}
$$

Balance equation of the total concentration of $\mathrm{Sr}(\mathrm{II})$ :

$$
\begin{aligned}
V \cdot[\mathrm{Sr}]_{0}= & V \cdot\left(\left[\mathrm{Sr}^{2+}\right]+\left[\mathrm{SrCO}_{3}^{0}\right]+\left[\mathrm{SrNO}_{3}^{+}\right]\right. \\
& \left.+\left[\mathrm{SrSO}_{4}^{0}\right]+\left[\mathrm{SrCO}_{3} \cdot \text { solid }\right]\right) \\
& +m \cdot\left(\left[\mathrm{SOSr}^{+}\right]+\left[(\mathrm{SO})_{2} \mathrm{Sr}^{0}\right]+\left[\mathrm{SOSrNO}_{3}^{0}\right]\right. \\
& \left.+\left[\mathrm{SOSrCO}_{3}^{-}\right]+\left[X_{2} \mathrm{Sr}\right]+\left[\mathrm{XSrNO}_{3}\right]\right) .
\end{aligned}
$$

Balance equation of nitrates:

$$
\begin{aligned}
V \cdot\left[\mathrm{NO}_{3}^{-}\right]_{0}= & V \cdot\left(\left[\mathrm{NO}_{3}^{-}\right]+\left[\mathrm{SrNO}_{3}^{+}\right]\right) \\
& +m\left(\left[\mathrm{SOSrNO}_{3}^{0}\right]+\left[\mathrm{XSrNO}_{3}^{0}\right]\right) .
\end{aligned}
$$

Balance equation of sulphates:

$\left[\mathrm{SO}_{4}^{2-}\right]_{0}=\left(\left[\mathrm{SO}_{4}^{2-}\right]+\left[\mathrm{SrSO}_{4}^{0}\right]\right)$.

It is assumed that sulphates are present only in solution.

Balance equation of carbonates:

$$
\begin{aligned}
V \cdot\left[\mathrm{CO}_{3}^{2-}\right]_{0}= & V \cdot\left(\left[\mathrm{CO}_{3}^{2-}\right]+\left[\mathrm{HCO}_{3}^{-}\right]\right. \\
& \left.+\left[\mathrm{H}_{2} \mathrm{CO}_{3}\right]+\left[\mathrm{SrCO}_{3}^{0}\right]\right) \\
& +m \cdot\left(\left[\mathrm{SOSrCO}_{3}^{-}\right]+\left[\mathrm{SOH}_{2} \mathrm{CO}_{3}^{-}\right]\right. \\
& \left.+\left[\mathrm{SOH}_{2} \mathrm{HCO}_{3}^{0}\right]\right) .
\end{aligned}
$$

where $V$ is the volume of the aqueous phase, $m$ is the mass of the solid phase, e.g. bentonite, and $[\mathrm{Sr}]_{0},\left[\mathrm{NO}_{3}^{-}\right]_{0},\left[\mathrm{SO}_{4}^{2-}\right]_{0}$ and $\left[\mathrm{CO}_{3}^{2-}\right]_{0}$ are the starting concentrations in the aqueous phase. If the partial pressure of $\mathrm{CO}_{2}, p \mathrm{CO}_{2}$, is taken into consideration then it holds ( $\mathrm{KpI}$ is the constant of equation (63) corrected for the given ionic strength, $I$ ):

$$
\left[\mathrm{CO}_{3}^{2-}\right]=\frac{p \mathrm{CO}_{2}}{\left(K p I \cdot\left[\mathrm{H}^{+}\right]^{2}\right)}
$$

and consequently, the concentrations of $\left[\mathrm{HCO}_{3}^{-}\right]$and $\left[\mathrm{H}_{2} \mathrm{CO}_{3}\right]$ are calculated by means of Eqs. (61) and (62), respectively.

Balance equation of the total concentration of the layer sites, $\underline{\Sigma X}$ :

$$
\Sigma X=2\left[X_{2} \mathrm{Sr}\right]+\left[\mathrm{XrNO}_{3}\right]+[X \mathrm{Na}]+[\mathrm{XH}]
$$

The solution of the set of equations mentioned above, namely for the given interval of $\mathrm{pH}$, lies in combinating the balance equations with the equilibrium constant equations, for example, the concentration $\left[\mathrm{SOSr}^{+}\right]$derived from Eq. (50) is inserted into Eqs. (66), (70) and (73), [X $\left.\mathrm{SrNO}_{3}\right]$ from Eq. (55) into Eq. (73) and (78), etc. The group of thus modified balance equations creates the regression function, the solution algorithm of which is depicted in Fig. 1.

It is evident that the algorithm consists of two loops: external and inner. In the external loop, the Newton-Raphson multidimensional non-linear regression procedure is used for fitting the experimentally determined data, and in the inner loop, the proper regression function is solved. In the last step, the functions $K d_{\mathrm{cal}}=\mathrm{f}(\mathrm{pH})$, Eq. (79), and \%Sorption $=\mathrm{f}(\mathrm{pH})$, Eq. (80), are evaluated.

$$
\begin{gathered}
K d_{\mathrm{cal}}=\frac{\left[\mathrm{SOSr}^{+}\right]+\left[(\mathrm{SO})_{2} \mathrm{Sr}^{0}\right]+\left[\mathrm{SOSrNO}_{3}^{0}\right]}{\left[\mathrm{Sr}^{2+}\right]+\left[\mathrm{SrCO}_{3}^{0}\right]+\left[\mathrm{SrNO}_{3}^{+}\right]+\left[\mathrm{SrSO}_{4}^{0}\right]} \\
+\frac{\left[\mathrm{SOSrCO}_{3}^{-}\right]+\left[\mathrm{X}_{2} \mathrm{Sr}\right]+\left[\mathrm{XSNO}_{3}\right]}{\left[\mathrm{Sr}^{2+}\right]+\left[\mathrm{SrCO}_{3}^{0}\right]+\left[\mathrm{SrNO}_{3}^{+}\right]+\left[\mathrm{SrSO}_{4}^{0}\right]}, \\
\% \text { Sorption }= \\
+\frac{m}{V}\left(\frac{\left[\mathrm{SOSr}^{+}\right]+\left[(\mathrm{SO})_{2} \mathrm{Sr}^{0}\right]+\left[\mathrm{SOSrNO}_{3}^{0}\right]}{\left[\mathrm{Sr}_{0}\right.}\right) \cdot 100 . \\
\left.+\mathrm{SOSrCO}_{3}^{-}\right]+\left[\mathrm{X}_{2} \mathrm{Sr}\right]+\left[\mathrm{XSrNO}_{3}\right]
\end{gathered}
$$

The sorption on the edge sites, Eq. (81), and layer sites Eq. (82), can also be calculated

$$
\begin{aligned}
\%_{\text {Sorption }}^{\text {edge sites }} & =\frac{m}{V} \cdot\left(\frac{\left[\mathrm{SOSr}^{+}\right]+\left[(\mathrm{SO})_{2} \mathrm{Sr}^{0}\right]}{[\mathrm{Sr}]_{0}}\right. \\
& \left.+\frac{\left[\mathrm{SOSrNO}_{3}^{0}\right]+\left[\mathrm{SOSrCO}_{3}^{-}\right]}{[\mathrm{Sr}]_{0}}\right) \cdot 100 \\
\%_{\text {Sorption }} \text { layer sites } & =\frac{m}{V} \cdot \frac{\left[\mathrm{X}_{2} \mathrm{Sr}\right]+\left[\mathrm{XSrNO}_{3}\right]}{[\mathrm{Sr}]_{0}} \cdot 100
\end{aligned}
$$

The goodness-of-fit is evaluated by the $\chi^{2}$-test, which is based on calculating the quantity $\chi^{2}$ according to Eq. (83):

$$
\chi^{2}=\sum_{i=1}^{N} \frac{(S S x)_{i}}{\left(s_{q}\right)_{i}^{2}} .
$$

where $(S S x)_{i}$ is the $i$ th-square of the deviation of the experimental value from the calculated value, $\left(s_{q}\right)_{i}$ is the relative standard deviation of the $i$-th experimental point, $\mathrm{N}\left(\equiv n_{p}\right)$ is the number of experimental points.

The value of $\chi^{2}$ is used for calculating the criterion WSOS/DF (weighted sum of squares divided by degrees of freedom) [9]:

$$
W S O S / D F=\frac{\chi^{2}}{n_{i}} \quad n_{i}=n_{p}-n,
$$

where $n_{i}$ is the number of degrees of freedom, $n_{p}$ is the number of experimental points and $n$ is the number of model parameters sought during the regression procedure.

If WSOS/DF $\leq 20$, then there is a good agreement between the experimental and calculated data, while, in the other case the fitting is regarded as unsatisfactory. As for $\left(s_{q}\right)_{i}$, on the basis of the corresponding experiments, the constant value for each experimental data point was assumed to be equal to 0.1 (in the case of the titration experiments) or 0.05 (in the case of the sorption experiments). 


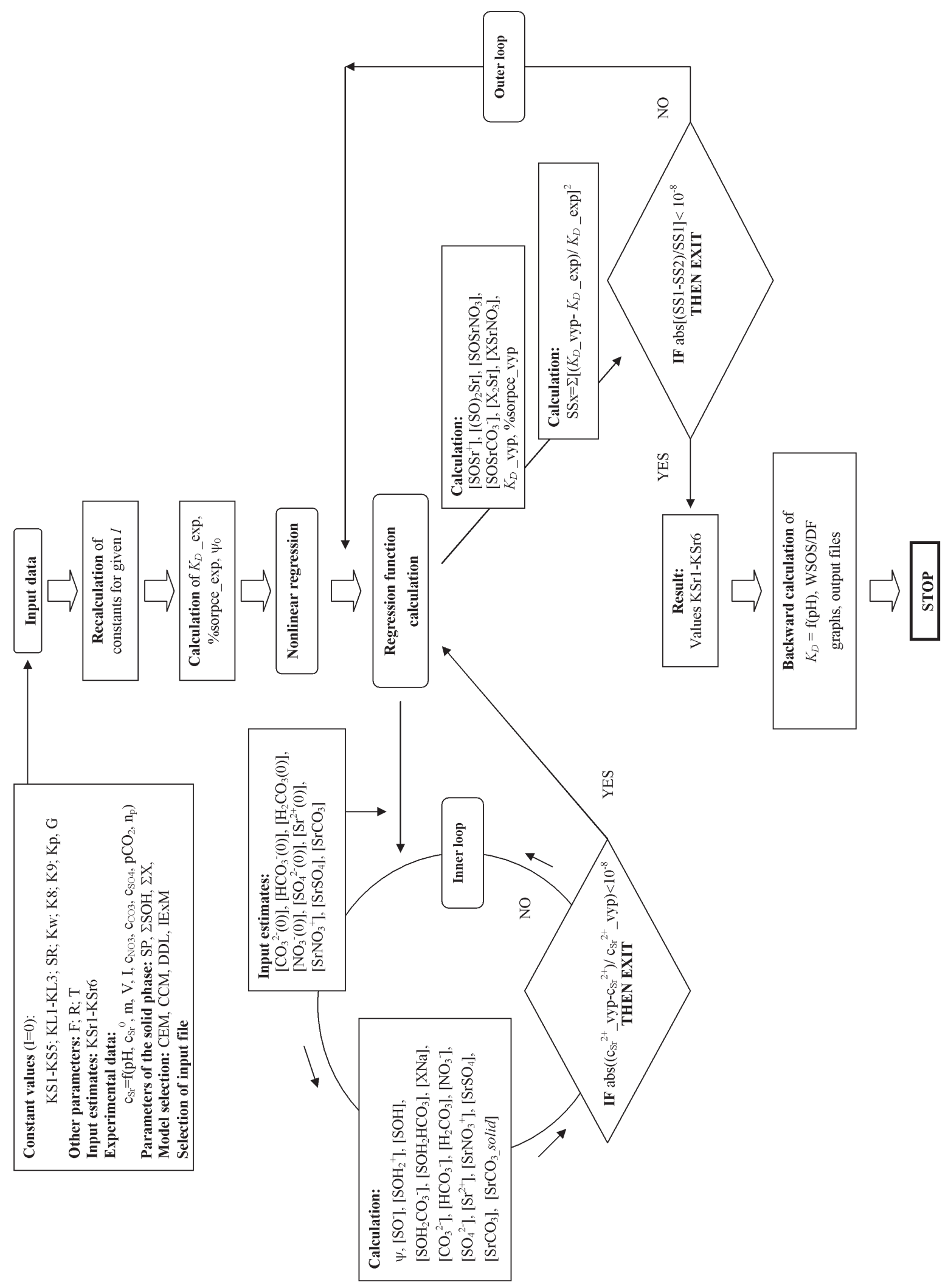




\section{Conclusions}

The constructed and debugged codes are collected in the STAMB-2003 package, namely the codes: (a) PSrSpec.fm determining the solution speciation, (b) P46dNLRG.fm for evaluating the titration curves, (d) PCsBen(Mag).fm and PSrBen(Mag).fm for evaluating the experimental sorption data by the Generalized Composite (GC) approach, (e) BeMagCs(Sr).fm assigned for the Component Additivity (CA) modeling approach.

The codes were successfully verified using the two systems, namely Sr-bentonite-magnetite and Cs-bentonite-magnetite, and the results were published at the international conference MIGRATION'03 [10], then at two home conferences [11, 12]. The final paper has been prepared for MIGRATION'05 [13].

In principle, the same procedure and algorithm as was described above can be used for modeling uptake processes of the SCMs+IExM type that occur on hydrated metal oxides, clay materials, etc.

\section{References}

[1] Wanner, H. et al.: "The Acid/Base Chemistry of Montmorillonite." Radiochimica Acta, Vol. 66/67 (1994), p. 157-162.

[2] Baeyens, B., Bradbury, M. H.: A Quantitative Mechanistic Description of Ni, Zn and Ca Sorption on Na-Montmorillonite, Part I: Physico-Chemical Characterisation and Titration Measurements, Report PSI Bericht Nr. 95-10, Villigen: Paul Scherrer Institut, 1995.

[3] Hurel, C. et al.: "Sorption Behaviour of Caesium on Bentonite Sample.” Radiochimica Acta, Vol. 90 (2002), p. 695-698.

[4] Kroupová, H.: „Studium sorpčních interakcí v systému: Bentonit - vybrané radionuklidy a produkty koroze kontejneru - podzemní voda.“ Doctoral thesis. Prague: Czech Technical University, 2004, p. 132.

[5] Ebert, K., Ederer, H.: Computeranwendungen in der Chemie, Weinheim: VCH Verlags GmbH, BRD, 1985.

[6] Štamberg, K. et al.: "Modelling and Simulation of Sorption Selectivity in the Bentonite- $\mathrm{HCO}_{3}^{-}-\mathrm{CO}_{3}^{2-}{ }^{233} \mathrm{U}(\mathrm{VI})$ Species System." Journal of Radioanalytical and Nuclear Chemistry, Vol. 241 (1999), No. 3, p. 487-492.

[7] Bradbury, M. H., Baeyens, B.: "Sorption of Eu on Naand Ca-montmorillonites: Experimental Investigations and Modelling with Cation Exchange and Surface Complexation." Geochimica et Cosmochimica Acta, Vol. 66 (2002), No. 13, p. 2325-2334.

[8] Missana, T., García-Gutiérres M., Fernńdez V.: Uranium (VI) Sorption on Colloidal Magnetite under Anoxic Environment: Experimental Study and Surface
Complexation Modelling. Geochimica et Cosmochimica Acta, Vol. 67 (2003), No. 14, p. 2543-2550.

[9] Herbelin, A. L., Westall, J. C.: "FITEQL - A Computer Program for Determination of Chemical Equilibrium Constants from Experimental Data, Version 3.2." Report 96-01. Corvallis, Oregon: Department of Chemistry, Oregon State University, 1996.

[10] Kroupová, H., Štamberg, K.: "Application of the Generalized Composite (GC) and Component Additivity (CA) Approaches for Modeling of $\mathrm{Cs}(\mathrm{I})$ and $\mathrm{Sr}(\mathrm{II})$ Sorption on Bentonite in the Presence of Corrosion Products Using Three Types of Surface Complexation Model." In: MIGRATION '03 Proceedings. Gyeongju, Korea: $9^{\text {th }}$ International Conference on Chemistry and Migration Behaviour of Actinides and Fission Products in the Geosphere, 2003, p. 100.

[11] Kroupová, H., Štamberg, K.: "Experimental Study and Mathematical Modeling of Cs(I) and $\mathrm{Sr}(\mathrm{I})$ Sorption on Bentonite as Barrier Material in Deep Geological Repository.” In: XVIIth Conference on Clay Mineralogy and Petrology Proceedings, 13-17 September 2004. (Štastný, M., ed.) Prague: Czech National Clay Group, 2004.

[12] Kroupová, H., Štamberg, K.: „Experimentální studium a povrchově-komplexační modelování sorpce Cs a $\mathrm{Sr}$ na bentonitu a magnetitu." Chemické listy, Vol. 98 (2004), No. 8, p. 570.

[13] Filipská, H., Štamberg, K.: "Parametric Study of the Sorption of $\mathrm{Cs}(\mathrm{I})$ and $\mathrm{Sr}(\mathrm{II})$ on Mixture of Bentonite and Magnetite Using SCM+IExM.” MIGRATION '05 $10^{\text {th }}$ International Conference on Chemistry and Migration Behavior of Actinides and Fission Products in the Geosphere, 18-23 September, Avignon, France, to be published in the Proceeding of MIGRATION '05.

Ing. Helena Filipská, Ph.D.

phone: +420224358225

fax: +420224358202

e-mail: filipska@fjfi.cvut.cz

Centre for Radiochemistry and Radiation Chemistry

Doc. Ing. Karel Štamberg, CSc., Ph.D.

phone: +420224358 205

fax: +420222320 861

e-mail: stamberg@fjfi.cvut.cz

Department of Nuclear Chemistry

Czech Technical University in Prague

Faculty of Nuclear Sciences and Physical Engineering

Břehová 7

11519 Praha 1, Czech Republic 